\title{
CUSTOS DE COMPRA E TRANSPORTE DE ETANOL: UM COMPARATIVO ENTRE A IMPORTAÇÃO E A AUTOPRODUÇÃO NO ESTADO DO RIO GRANDE DO SUL
}

Semana Online Científica de Engenharia, 1ạ edição, de 25/10/2021 a 27/10/2021

ISBN dos Anais: 978-65-81152-19-2

MORO; Felipe ${ }^{1}$, SANTOS; Rodrigo Romano dos ${ }^{2}$, PICCININ; Yvelise ${ }^{3}$

\section{RESUMO}

No Brasil, o Sudeste destaca-se como eixo de maior produção de etanol, sendo São Paulo o estado com maior destaque. Em estados distantes deste eixo, os preços deste combustível são majorados. Deste modo, o objetivo do estudo consiste em identificar a viabilidade de compra e transporte de etanol produzido a partir da cana-de-açúcar de São Paulo, em relação à compra e transporte de etanol de possíveis indústrias que podem vir a se instalar no estado do Rio Grande do Sul (etanol lignocelulósico da GranBio, etanol lignocelulósico e amiláceo da Raízen e etanol lignocelulósico da Abengoa), relacionando as opções de compra até uma empresa receptora na cidade de Santa Maria - RS, para a distribuição regional. O estudo considerou o preço mínimo de comercialização em dólares americanos por litros comprados, o custo de transporte associado a cada estimativa de distância para as 4 usinas em dólares por litro transportados, a quantidade de viagens que podem ser feitas de cada rota diariamente, em um abastecimento de pelo menos 30 viagens mensais de carga de biocombustível para Santa Maria e, por fim, a capacidade produtiva das 4 indústrias, as quais devem fornecer pelo menos a demanda estimada de etanol para a cidade de Santa Maria. A natureza da pesquisa consiste em aplicada, com abordagem quantitativa, descritiva e coleta de dados documental, aplicando-se os fundamentos de modelagem e otimização típicos da pesquisa operacional, mais especificamente da programação linear para a resolução da problemática estabelecida. Destaca-se também que os cálculos são irrestritos a região de estudo, sendo adaptáveis à qualquer região nacional. Os resultados do estudo demonstraram que houve uma redução de $12 \%$ no custo total mensal, pela influência da produção local e, essencialmente, pela menor distância de transporte dentro do estado gaúcho. Define-se que é inviável importar etanol de São Paulo para Santa Maria.

PALAVRAS-CHAVE: Etanol, Pesquisa Operacional, Programação Linear, Viabilizar 